\title{
EMBRYO TRANSFER IN THE SHEEP: THE SIGNIFICANCE OF SYNCHRONIZING OESTRUS IN THE DONOR AND RECIPIENT ANIMAL
}

\author{
L. E. A. ROWSON AND R. M. MOOR \\ A.R.C. Unit of Reproductive Physiology and Biochemistry*, University of Cambridge
}

(Received 22nd Fune 1965)

\begin{abstract}
Summary. Morulae and blastocysts obtained from ewes 5, 7 and 9 days after oestrus were transferred to 120 recipients whose oestrous cycles were either synchronized or \pm 2 or 3 days out of phase relative to the onset of oestrus in the donors.

When synchronization was exact $75 \%$ of all recipients became pregnant. A high proportion of pregnancies were, in general, also obtained where the onset of oestrus in the recipient differed from that of the donor by \pm 2 days. With a difference of \pm 3 days, however, only $8 \%$ of ewes became pregnant. The survival of 5-day morulae transferred to 7-day recipients was lower than when 9-day blastocysts were transferred to 11 -day recipients.

The results are discussed with reference to possible factors associated with early embryonic mortality.
\end{abstract}

\section{INTRODUCTION}

It is generally believed that the onset of oestrus in donor and recipient sheep must be closely synchronized in order to obtain the maximal survival of transferred eggs (Hunter, Adams \& Rowson, 1955; Averill \& Rowson, 1958; Moore \& Rowson, 1960; Hancock \& Hovell, 1961). However, it was not until the recent study of Moore \& Shelton (1964) that the effect of the degree of synchronization on the survival of transferred eggs was experimentally determined. They found that eggs transferred during the first 3 days after oestrus developed most successfully in recipient ewes first observed in oestrus within $12 \mathrm{hr}$ of their respective donors.

The progesterone concentration in the ovarian venous blood rises rapidly during the 6 days after oestrus (Edgar \& Ronaldson, 1958) and, at the same time, the endometrium undergoes characteristic changes which develop with such rapidity that it would be surprising if a close degree of synchronization were not necessary for the survival of transferred eggs. The concentration of progesterone reaches a maximum on about the 7 th day after oestrus (hereafter referred to as Day 7) and this level remains relatively constant until Day 15. It might be expected, therefore, that for successful transfers during the latter period of the cycle a much wider range of asynchrony between the donor and

* Postal address: Animal Research Station, 307 Huntingdon Road, Cambridge. 
recipient should be possible. The experiments were therefore designed to investigate this particular aspect of egg transfer in the sheep.

\section{Donors}

\section{MATERIALS AND METHODS}

Eighty-six ewes of the Dorset Horn, Suffolk or Welsh breeds were used as donors. They were superovulated by an injection of 800 to 1000 i.u. of PMS on Day 12 and subsequently placed with a raddled fertile ram and examined for service marks every $8 \mathrm{hr}$ at 08.00 hours, 16.00 hours and midnight.

Morulae and blastocysts were obtained from the donors on either the 5 th or 7 th day after the onset of oestrus using the technique described by Hunter, Adams \& Rowson (1955). The only difference in our technique was that a much greater proportion of each uterine horn was flushed than in the earlier experiments. The flushing medium was 5 to $10 \mathrm{ml}$ sterile, homologous sheep serum stored at $-20^{\circ} \mathrm{C}$ but warmed to $37^{\circ} \mathrm{C}$ before use.

For the recovery of 9-day blastocysts the entire uterus of the donor ewe was flushed. This was carried out by clamping the cervix with bowel forceps to prevent leakage of serum, introducing the needle of the flushing syringe into the tip of one horn and gently flushing the whole uterus; the flushing medium containing the embryos was collected via a cannula introduced into the contralateral oviduct. The morulae and blastocysts were held in sterile serum at $37^{\circ} \mathrm{C}$ pending transfer, and the maximum interval between collection and transfer was $3 \mathrm{hr}$.

\section{Recipients}

One hundred and twenty non-pregnant Welsh Mountain and Suffolk ewes were used as recipients. These ewes were run with vasectomized rams marked with coloured grease and were examined for evidence of oestrus at 8-hourly intervals as in the case of the donor ewes. Two morulae or blastocysts were transferred to one uterine horn of each recipient using the technique described by Hunter, Adams \& Rowson (1955).

\section{Experimental design}

Morulae and blastocysts which had been obtained from donor ewes on Days 5, 7 and 9 after the onset of oestrus, (hereafter referred to as 5-day morulae, 7-day blastocysts and 9-day blastocysts) were transferred to five groups of recipients in which oestrus had occurred 2 to 12 days previously (hereafter referred to as 2-day recipient, 3-day recipient, etc.). The time relationship between the onset of oestrus in the donors and in the recipients of each group was as follows:

Group 1. Donors in oestrus 3 days before the recipient: 5 -day morulae transferred to 2-day recipient; 7-day blastocysts transferred to a 4-day recipient; and 9-day blastocysts transferred to a 6-day recipient.

Group 2. Donors in oestrus 2 days before the recipient: 5-day morulae transferred to a 3-day recipient; 7-day blastocysts transferred to a 5-day recipient; and 9-day blastocysts transferred to a 7-day recipient. 
Group 3. (Control) donors in oestrus at the same time as recipient: 5-day morulae transferred to a 5-day recipient; 7-day blastocysts transferred to a 7-day recipient; and 9-day blastocysts transferred to a 9-day recipient.

Group 4. Donors in oestrus 2 days after the recipient: 5 -day morulae transferred to a 7-day recipient; 7-day blastocysts transferred to a 9-day recipient; and 9-day blastocysts transferred to an 11-day recipient.

Group 5. Donors in oestrus 3 days after the recipient: 5-day morulae transferred to an 8-day recipient; 7-day blastocysts transferred to a 10-day recipient; and 9-day blastocysts transferred to a 12-day recipient.

Transfers were only carried out when the difference between the time of onset of oestrus in the donor and recipient ewes was within $8 \mathrm{hr}$ of the times specified in each of the experimental groups.

The ages of all transferred morulae and blastocysts and the stage of development of the uterus of the recipients were calculated in these experiments as from the day of onset of oestrus-Day 0 of the cycle. As ovulation does not occur until about $24 \mathrm{hr}$ after the onset of oestrus the actual age of the embryos was 1 day less than that given in the text.

\section{RESULTS}

The influence of the degree of synchronization between the donor and recipient upon the development of morulae recovered 5 days after the onset of oestrus is shown in Table 1.

TABLE 1

EFFECT OF THE DEGREE OF SYNCHRONIZATION OF OESTRUS IN DONOR AND RECIPIENT EWES UPON THE SURVIVAL OF MORULAE REGOVERED 5 DAYS AFTER THE ONSET OF OESTRUS

\begin{tabular}{c|c|c|c|c}
\hline $\begin{array}{c}\text { Interval between oestrus } \\
\text { and operation (days) }\end{array}$ & \multicolumn{2}{|c|}{$\begin{array}{c}\text { No. of recipients } \\
\text { (two morulae/recipient) }\end{array}$} & \multirow{2}{*}{$\begin{array}{c}\text { No. of } \\
\text { lambs } \\
\text { born }\end{array}$} \\
\cline { 1 - 2 } Donor & Recipient & Total & Pregnant & \\
\cline { 1 - 2 } 5 & 2 & 8 & 1 & 1 \\
5 & 3 & 8 & 6 & 10 \\
5 & 5 & 8 & 6 & 10 \\
5 & 7 & 8 & 1 & 2 \\
5 & 8 & 8 & 0 & 0 \\
\hline
\end{tabular}

Although the best results were obtained when the onset of oestrus in the donor and recipient was exactly synchronized, the transfer of morulae to recipients that were in oestrus up to 2 days after their respective donors also gave good results. On the other hand, the transfer of morulae to recipients which had been in oestrus 2 days before their respective donors resulted in only one out of eight ewes becoming pregnant. Where the difference between the onset of oestrus in donor and recipient was 3 days the survival rate of morulae was equally low.

The influence of the degree of synchronization between the donor and recipient upon the development of blastocysts recovered 7 days after the onset of oestrus is shown in Table 2. 
As in the case of the 5-day morulae, maximal survival of 7-day blastocysts occurred when the recipients were in oestrus within $8 \mathrm{hr}$ of their respective donors.

When the onset of oestrus in the recipient differed by \pm 2 days from that of the donor, i.e. where oestrus occurred in the recipients on Day 5 or Day 9, conditions in the uterus appeared to be still relatively favourable for the transferred 7-day blastocysts. However, similar blastocysts did not survive when transferred to recipients which were in heat 3 days before or after their respective donors.

\section{TABLE 2}

EFFECT OF THE DEGREE OF SYNCHRONIZATION OF OESTRUS IN DONOR AND RECIPIENT EWES UPON THE SURVIVAL OF BLASTOCYSTS REGOVERED 7 DAYS AFTER THE ONSET OF OESTRUS

\begin{tabular}{c|c|c|c|c}
\hline \multicolumn{2}{c|}{$\begin{array}{c}\text { Interval between oestrus } \\
\text { and operation (days) }\end{array}$} & \multicolumn{2}{|c|}{$\begin{array}{c}\text { No. of recipients } \\
\text { (two blastocysts/recipient) }\end{array}$} & $\begin{array}{c}\text { No. of } \\
\text { lambs } \\
\text { born }\end{array}$ \\
\cline { 1 - 2 } Donor & Recipient & Total & Pregnant & \\
\hline 7 & 4 & 8 & 1 & 1 \\
7 & 5 & 8 & 6 & 7 \\
7 & 7 & 8 & 7 & 10 \\
7 & 9 & 8 & 4 & 5 \\
7 & 10 & 8 & 0 & 0 \\
\hline
\end{tabular}

TABLE 3

EFFECT OF THE DEGREE OF SYNCHRONIZATION OF OESTRUS IN DONOR AND RECIPIENT EWES UPON THE SURVIVAL OF BLASTOCYSTS REGOVERED 9 DAYS AFTER THE ONSET OF OESTRUS

\begin{tabular}{c|c|c|c|c}
\hline \multicolumn{2}{c|}{$\begin{array}{c}\text { Interval between oestrus } \\
\text { and operation (days) }\end{array}$} & \multicolumn{2}{c|}{$\begin{array}{c}\text { No. of recipients } \\
\text { (two blastocysts/recipient) }\end{array}$} & $\begin{array}{c}\text { No. of } \\
\text { lambs } \\
\text { born }\end{array}$ \\
\cline { 1 - 2 } Donor & Recipient & Total & Pregnant & \\
\cline { 1 - 3 } 9 & 6 & 8 & 0 & 0 \\
9 & 7 & 8 & 4 & 6 \\
9 & 9 & 8 & 5 & 8 \\
9 & 11 & 8 & 6 & 9 \\
9 & 12 & 8 & 0 & 0 \\
\hline
\end{tabular}

The influence of the degree of synchronization between the donor and recipient upon the development of blastocysts recovered 9 days after the onset of oestrus is shown in Table 3.

The results obtained following the transfer of 9-day blastocysts were very similar to those obtained with the 5-day morulae and 7-day blastocysts. The one exception was that where oestrus in the recipients was 2 days in advance of that in the donors the results were slightly better than in the synchronized ewes. When the difference between the onset of oestrus in the donor and recipient was extended to \pm 3 days no pregnancies followed the transfer of 9-day blastocysts. 
An analysis of variance carried out to test the effect of altering the degree of synchronization of oestrus in the donor and recipient upon the survival of transferred embryos showed that there was, indeed, a slight change in the mode as the age of the embryos increased. This is shown diagrammatically in Textfig. 1 .

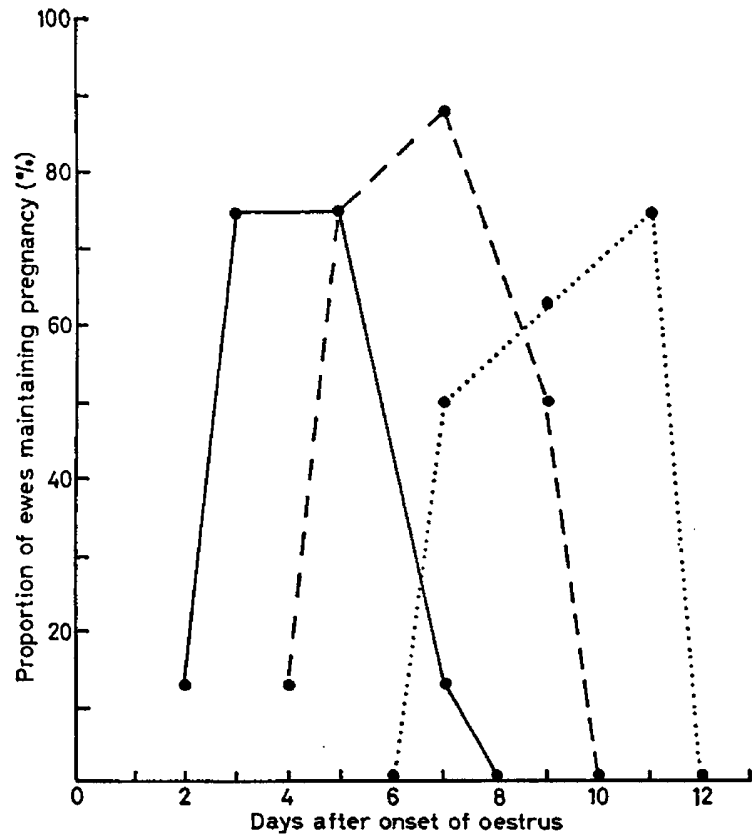

TEXT-FIG. 1. The proportion of recipient ewes becoming pregnant following the transfer of 5-day morulae $(--)$, 7-day blastocysts (- - ) and 9-day blastocysts $(\cdots)$ at different stages of the oestrous cycle.

\section{DISCUSSION}

The results of this study, particularly when considered in conjunction with those of Moore \& Shelton (1964), clearly indicate that close synchronization is a prerequisite for normal development of sheep embryos transferred between the 2nd and 11th day after oestrus. No embryos survived in recipients which were in oestrus 3 days prior to their respective donors and only $8 \%$ survived where the recipients showed oestrus 3 days after the donors. On the other hand, when the stage of development of the uterus and embryo differed by only 2 days, a high percentage of embryos did survive. In fact, under these conditions, the proportion of embryos surviving was almost as high as in closely synchronized animals.

As mentioned earlier, the progesterone level in the ovarian venous blood of sheep shows little variation during the period extending from Day 7 to Day 15 after oestrus. Yet, despite a relatively constant level of progesterone during that period the endometrium or its secretion must, presumably, be undergoing continuous and rapid changes so that if the embryo and the endometrium are out of phase by 3 days the embryo will not survive. 
There are two possible explanations for the embryonic loss which occurs when the donor and recipient ewe are not closely synchronized. The most likely reason why an 'out-of-phase' embryo dies is that the uterine environment may not be suitable for it. Another possibility, however, is that the 'out-of-phase' embryo is incapable of exerting a sufficient luteotrophic action on the recipient's corpus luteum, with the result that the corpus luteum is not maintained. It may well be that conditions, similar to those artificially created in our transfer experiments, may occur in certain cases of temporary infertility in ruminants.

Our results are, on the whole, similar to those obtained in the rabbit (Chang, 1950) and rat (Noyes \& Dickmann, 1960). Chang found that a difference of more than 2 days consistently resulted in death of the transferred eggs. Noyes \& Dickmann (1960) suggested that the relationship between the developmental stages of the egg and uterus in the rat becomes most critical at the time of implantation. In mice, on the other hand, McLaren \& Michie (1956) and Doyle, Gates \& Noyes (1963) showed that transferred eggs develop more successfully in a uterine environment which is less advanced than that of the donor animal. However, in all of these three species, synchronization appears to be even more critical than in the sheep.

In most of the non-synchronous egg transfers in laboratory animals the loss of the embryos appears to take place at, or just prior to, implantation. In the sheep, on the other hand, where implantation does not take place until long after the normal cyclical regression of the corpus luteum, the position appears to be different. Further experiments are being undertaken to determine the fate of the 'out-of-phase' embryos and the reason why they fail to develop.

\section{ACKNOWLEDGMENTS}

We are indebted to the staff at the Unit, and particularly to $\mathrm{Mr} \mathrm{H}$. Strange for his help throughout the experiments. We would like to thank Dr T. R. R. Mann for his continuous encouragement and for reading and discussing the manuscript with us.

\section{REFERENCES}

Averill, R. L. W. \& Rowson, L. E. A. (1958) Ovum transfer in the sheep. F. Endocr. 16, 326.

Chang, M. C. (1950) Development and fate of transferred rabbit ova or blastocyst in relation to the ovulation time of recipients. F. exp. Zool. 114, 197.

Doyle, L. L., Gates, A. H. \& Noyes, R. W. (1963) Asynchronous transfer of mouse ova. Fert. Steril. $14,215$.

Edgar, D. G. \& Ronaldson, J. W. (1958) Blood levels of progesterone in the ewe. F. Endocr. 16, 378.

Hancock, J. L. \& Hovell, G. J. R. (1961) Transfer of sheep ova. 7. Reprod. Fert. 2, 295.

Hunter, G. L., Adams, C. E. \& Rowson, L. E. A. (1955) Interbreed ovum transfer in sheep. F. agric. Sci. $46,143$.

Malaren, A. \& Michie, D. (1956) Studies on the transfer of fertilised mouse eggs to uterine fostermothers. 1. Factors affecting the implantation and survival of native and transferred eggs. 7. exp. Biol. 33, 394.

Moore, N. W. \& Rowson, L. E. A. (1960) Egg transfer in sheep. Factors affecting the survival and development of transferred eggs. F. Reprod. Fert. $1,332$.

Moore, N. W. \& Shelton, J. N. (1964) Egg transfer in sheep. Effect of degree of synchronization between donor and recipient, age of egg, and site of transfer on the survival of transferred eggs. 7. Reprod. Fert. 7, 145.

Noyes, R. W. \& Dickmann, Z. (1960) Relationship of ovular age to endometrial development. J. Reprod. Fert. 1, 186. 